\title{
Intake of Minerals from Food Supplements in a German Population-A Nationwide Survey
}

\author{
Janina Willers1, Michaela Heinemann1, Norman Bitterlich², Andreas Hahn1 \\ ${ }^{1}$ Institute of Food Science and Human Nutrition, Leibniz University, Hannover, Germany \\ ${ }^{2}$ Medizin \& Service GmbH, Department of Biostatistics, Chemnitz, Germany \\ Email: hahn@nutrition.uni-hannover.de
}

Received 13 January 2015; accepted 31 January 2015; published 4 February 2015

Copyright (C) 2015 by authors and Scientific Research Publishing Inc.

This work is licensed under the Creative Commons Attribution International License (CC BY). http://creativecommons.org/licenses/by/4.0/

(c) (i) Open Access

\begin{abstract}
Introduction: Studies indicate that $17.9 \%-60 \%$ of adults in Germany and Europe regularly use food supplements. Some reports suggest that their use might be responsible for excessive nutrient intake. The purpose of this survey was to examine the quantitative mineral intakes from food supplements: whether the tolerable upper intake levels (ULs) with supplements alone, or in combination with food was exceeded was checked. Methods: The survey was carried out by the Association for Consumer Research, Nürnberg, Germany. Anonymous data of 1070 supplement users (40.8\% men, 59.2\% women) aged 18 - 93 years were available. Three groups were examined based on dietary and supplemental mineral intakes: average, middle-high and high intake. Results: The mean number of supplements reported was $1.6 \pm 1.1$ products in men and $1.5 \pm 0.9$ products in women. The minerals most frequently consumed were magnesium, followed by calcium, zinc and selenium. The percentage of the supplement users with total intakes greater than the UL was minimal for all minerals. Supplement use in 143 cases increased the likelihood of intakes above the UL only for magnesium. Subjects particularly in the high intake group-as a worst case scenario-had intakes above the $U L$ in the case of calcium $(n=23)$ and zinc $(n=34)$. The percentage of subjects taking several products was greater in subjects exceeding the UL than in those below (P $<0.001)$. Multiple use was seen significantly more often in men than in women $(P<0.01)$. Conclusions: In this survey, supplement use was generally not associated with excessive intake. Supplement use resulted in intakes above the $\mathrm{UL}$ in only a few cases relating to magnesium, calcium and zinc. This applies more often to elderly subjects and particularly to those who already have a high mineral intake from food in the model calculation.
\end{abstract}

\section{Keywords}

Food Supplements, Minerals, Survey, Tolerable Upper Intake Level, Multiple Uses 


\section{Introduction}

Food supplements are regularly used by the adult population. Consumption of supplements in Germany and other European countries ranged between $17.9 \%$ and $60 \%$ of the population [1]-[9].

According to the European legal definition (food supplement directive 2002/46/EC), food supplements are foodstuffs in the form of capsules, tablets, pills, and other similar forms, which are intended to supplement the normal diet. Food supplements and related product groups are concentrated sources of nutrients, mainly vitamins, minerals and trace elements, but increasingly also other substances, such as plant extracts or essential fatty acids [10] [11] with a nutritional or physiological effect, alone or in combination.

In the last few years, the use of food supplements has been controversially discussed in view of expected benefits versus possible risks [7] [12]-[14]. There is certain evidence that excessive intake of specific nutrients can cause adverse effects [15]. Based on this background, maximum intake levels have been established for most vitamins and minerals. The tolerable upper intake level (UL) is the maximum level of total chronic daily intake of a nutrient from all sources that can be safely taken without risking an overdose or serious side-effects [16]. The taking of several products at the same time has also been discussed as a potential risk of excessive nutrient intake. The risk of excessive intake, particularly of calcium, magnesium, iron, and zinc, has been related to supplement use [13] [17] [18]. In this context, several aspects need to be considered: a) total supply from all dietary sources, b) short term use vs. lifetime use, c) high variability due to the amounts of vitamins or minerals, and d) the small difference between intake recommendation and UL.

The aim of this survey was to record the use of all food supplements systematically regarding each individual's intake habits. The incidence of multi-exposure and its influence on the total nutrient intake was specifically investigated. Whether or not an UL exceedance has occurred was checked. Additionally, a detailed observation of those subjects who exceeded UL with food supplement intake only and those with intake from food and supplements was made. The qualitative evaluations about the mineral intake are shown in this publication; the results about the vitamin intake will be published separately.

\section{Methods}

The project has been coordinated by the Institute of Food Science and Human Nutrition, Leibniz University Hannover, Germany. This included in particular the questionnaire preparation, product research, data preparation, and statistical analysis. The survey was conducted by the Association for Consumer, Marketing and Sales Research (GfK, Nürnberg, Germany) and took place in two waves (summer: 10-17 and 24-31 August 2012, winter: 22 February to 8 March 2013). Personal interviews (face-to-face) by experienced and trained interviewers using CAPI (Computer Assisted Personal Interview) as part of an omnibus survey (multiple topic survey) in the households of the consumers, as well as identical online interviews took place. The interviewees were representatively selected for the face-to-face interviews on the basis of official statistics based on state, city size, gender, age, household size, and occupation of the head of the household. The online respondents were selected through a representative consumer panel of GfK and were selected for supplementary use.

All participants were informed about the intended research and the anonymity of their data. GfK emphasised compliance with ethical practice and professional standards as well as data protection regulations. The questionnaire was performed on the basis of both national (ADM: ArbeitskreisDeutscherMarkt- und Sozialforschungsinstitutee.V.) and international (Esomar: worldwide society for social and market research, CASRO: Code of Standards and Ethics for Survey Research) market research industry guidelines.

The questionnaire included both personal and general demographic questions (e.g. age, gender, income, education, household size), as well as a specific part regarding supplement consumption. The product-specific information (product name, pack size, manufacturer, European Article Number (EAN), or Pharmazentralnummer (PZN)), consuming behaviour and consuming rationale for each product mentioned were retrieved and analysed. The individual nutrient composition of each product was investigated using the product-specific information. When products had unclear or incomplete information that could not be unambiguously assigned to a specific product, we referred to the composition of a comparable standard product with a listed highest dose.

The average daily intake for each individual nutrient was calculated by using the nutrient composition as unit/day multiplied by the respective taking habits (frequency of intake: daily (factor *1), 3 - 4 times/week (factor *3.5/7), 3 - 4 times/month (factor *3.5/30.4), or very irregularly (factor *12/365); seasonal supply: all year (factor *1), only in summer (factor *6/12), only in winter (factor *6/12), only on special occasions, e.g. sickness 
(factor *3/12)). A sample calculation for a preparation containing $5 \mu$ g vitamin $\mathrm{D}$, which has been used several times a week ( 3 - 4 times/week) and only in winter is: $5 \mu \mathrm{g} \times 3.5 / 7 \times 6 / 12=1.25 \mu \mathrm{g}$ vitamin D average daily intake. Information regarding the duration of intake were recorded as: $<3$ months, $\geq 3$ to $<6$ months, $\geq 6$ to $<12$ months, $\geq 1$ to $<5$ years, $\geq 5$ to $<10$ years, and $\geq 10$ years.

Drugs containing micronutrients were excluded from the analysis. Only food supplements, food for special medical purposes in the form of capsules and dietetic food have been considered as food supplements.

National reference values for nutritional intake were used for the comparison of the mineral intake calculated with the recommended dietary intake [19]. The data for the nutrient intake from food was conducted from the National Nutrition Survey II published in 2008 [9]. The $50^{\text {th }}$ and $95^{\text {th }}$ percentile of mineral intake from food were used based on this survey. Total mineral intake was calculated for three groups based on dietary intakes and the use of food supplements: average intake (the sums of the $50^{\text {th }}$ percentile from food and the $50^{\text {th }}$ percentile from supplements), middle-high intake $\left(50^{\text {th }}\right.$ percentile food plus $95^{\text {th }}$ percentile supplements) or high intake $\left(95^{\text {th }}\right.$ percentile food plus $95^{\text {th }}$ percentile supplements). The high intake group was interpreted as a "worst case scenario”. Nutrient intake data as a share of total population were not available for selenium, copper, chromium, manganese, or molybdenum.

The proportion of subjects exceeding UL was calculated for each nutrient to assess the general risk of excessive mineral intake from food supplements. Similar to other studies [7] [13], we used the UL defined by the European Food Safety Authority (EFSA) when available [16], or the UL from the Food Nutrition Board (FNB) of the Institute of Medicine (IOM) [20] [21]. The ULs are based on total nutrient intake from food and supplements, except for magnesium, for which the UL (250 mg/d) defined by the EFSA is based on intake from supplements only [16] [22].

The data acquisition was carried out by using input masks in Microsoft Excel 2010, and IBM SPSS Statistics (Version 21.0) for statistical analyses. Descriptive results were determined as case number, mean, standard deviation, $5^{\text {th }}$ percentile, median $\left(50^{\text {th }}\right.$ percentile $), 95^{\text {th }}$ percentile, maximum, and percentage. The chi-square test was used to test for statistically significant differences between two groups. There are nonparametric distributions of the intakes for all nutrients. Therefore, the Mann-Whitney U test was used for the comparison of intakes between specific groups. Statistical significance was generally accepted at $\mathrm{P} \leq 0.05$. This research was in compliance with the Declaration of Helsinki.

\section{Results}

\subsection{Characteristics of the Supplement Users}

A total of $n=4963$ men and women were interviewed via CAPI, of which only $n=804$ (16.2\%) used supplements. Extra online surveys took place in order to achieve a desired sample size of $n=1250$ respondents. This provided data from another $n=623$ supplement users. Overall, the $n=1427$ supplement users surveyed named $n$ $=2352$ products, of which $n=738$ (31.4\%) were not taken into account in the further analysis as they were not declared as food supplements or similar dietetic foods, or they could not be adequately characterized. The flow chart (Figure 1) illustrates the structure of our study population of supplement users analysed $(n=1070)$.

Characteristics of this collective are shown in Table 1 . The ratio of women to men in the face-to-face interviews (62.0\% vs. $38.0 \%$, respectively) was compared to that in the online surveys (55.9\% vs. $44.1 \%$, respectively) and the difference was statistically significant $(\mathrm{P}<0.05)$. The proportion of women predominated in both types of surveys. The average age of the supplement users was $54.5 \pm 14.9$ years (18 - 93 years). The majority of respondents (68.8\%) consumed only one product. The average intake of different supplements reported was 1.6 \pm 1.1 products in men and $1.5 \pm 0.9$ products in women; this gender difference was not significant. Of the products mentioned, $60.7 \%$ contained one or more minerals (12.7\% exclusively minerals, $48.0 \%$ minerals and/or vitamins and/or other substances). Further descriptive data in relation to this survey has already been published [23].

\subsection{Characteristics of Supplement Use}

Magnesium (59.2\% of all supplement users), calcium (37.0\%), zinc (33.6\%), and selenium (23.0\%) were the most frequently consumed minerals. All other minerals were from products supplied by less than $20 \%$ of the respondents (Table 2). There were no significant differences between the incidence of mineral intake between 


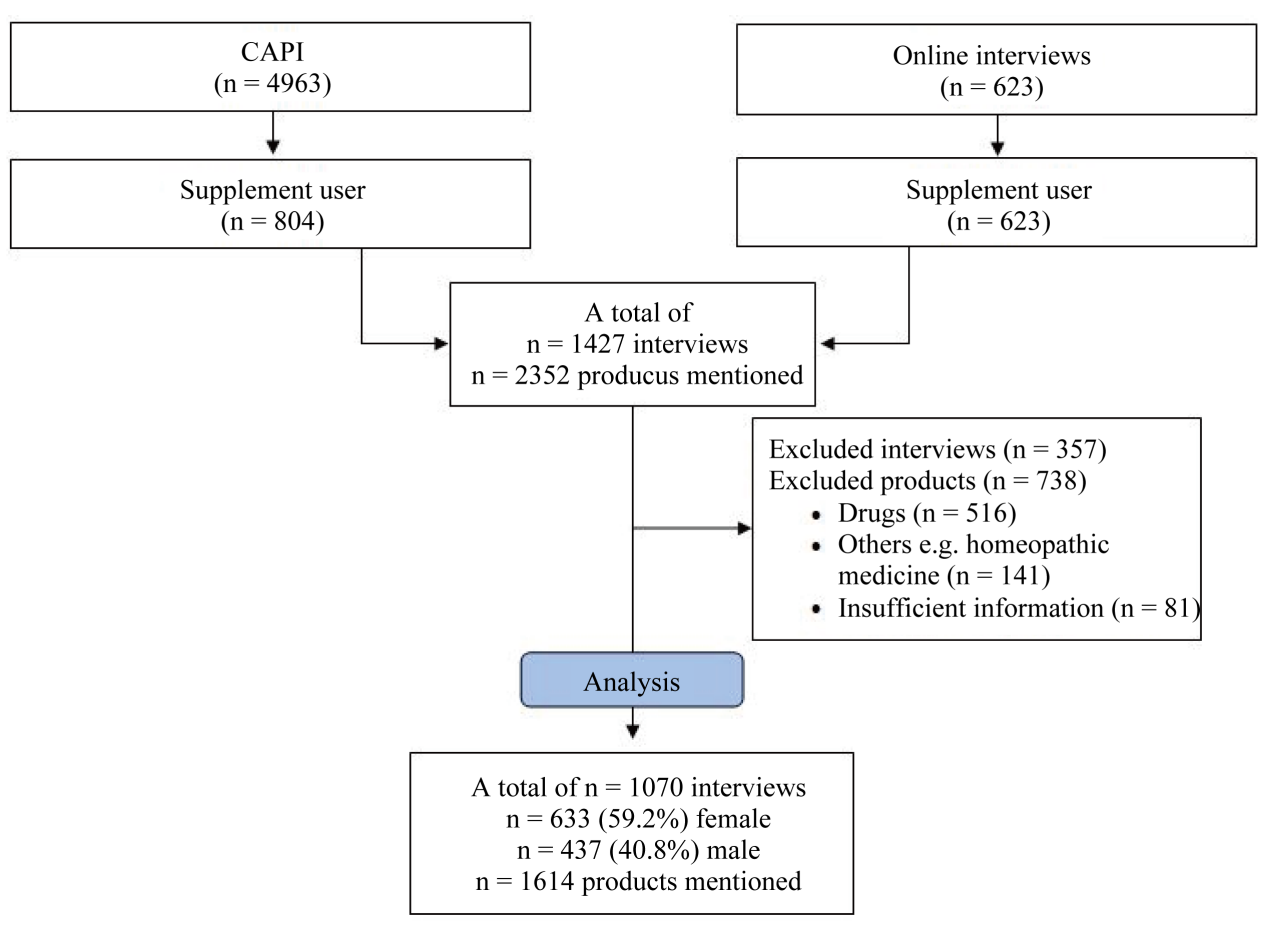

Figure 1. Flow chart of the survey.

Table 1. Characteristics of the supplement users $(n=1070)$.

\begin{tabular}{lcc}
\hline Characteristics & Number of subjects [n] & Percentage [\%] \\
\hline Gender & 437 & 40.8 \\
Men & 633 & 59.2 \\
Women & & \\
Age [years] & 26 & 2.4 \\
18 - 24 & 99 & 9.3 \\
25 - 34 & 292 & 27.3 \\
35 - 50 & 354 & 33.1 \\
51 - 64 & 299 & 27.9 \\
$\geq 65$ & & \\
Size of household & 269 & 25.1 \\
1 person & 494 & 46.2 \\
2 persons & 159 & 14.9 \\
3 persons & 108 & 10.1 \\
4 persons & 40 & 3.7 \\
5 persons & & 20.4 \\
Education & 295 & 40.2 \\
Lower secondary school & 430 & \\
Higher secondary school & & \\
Baccalaureate & & \\
Completed academic study & & \\
\hline
\end{tabular}


Table 2. Mineral intake only from food supplements among all supplement users ( $\mathrm{n}=1070)$.

\begin{tabular}{|c|c|c|c|c|c|c|c|c|c|}
\hline & \multicolumn{2}{|c|}{$\begin{array}{c}\text { Current } \\
\text { national } \\
\text { reference value }\end{array}$} & \multirow[t]{2}{*}{$\begin{array}{c}\% \text { of } \\
\text { supplement } \\
\text { users taking } \\
\text { specific } \\
\text { mineral }\end{array}$} & \multirow[t]{2}{*}{ Mean \pm SD } & \multirow[t]{2}{*}{$\begin{array}{c}5^{\text {th }} \\
\text { percentile }\end{array}$} & \multirow[t]{2}{*}{ Median } & \multirow[t]{2}{*}{$\begin{array}{c}95^{\text {th }} \\
\text { percentile }\end{array}$} & \multirow[t]{2}{*}{ Maximum } & \multirow{2}{*}{$\begin{array}{c}\text { Supplemen } \\
\text { users } \geq 95^{\text {th }} \\
\text { percentile } \\
\text { n (\%) }\end{array}$} \\
\hline & $\mathrm{m}$ & $\mathrm{w}$ & & & & & & & \\
\hline Calcium [mg/d] & \multicolumn{2}{|c|}{1000} & 37.0 & $275.6 \pm 273.1$ & 2.2 & 170.0 & 807.5 & 1300.0 & $19(4.8)$ \\
\hline Phosphorus [mg/d] & \multicolumn{2}{|c|}{700} & 13.0 & $87.1 \pm 60.1$ & 1.0 & 105.0 & 133.0 & 450.0 & $22(15.8)$ \\
\hline Magnesium [mg/d] & $350^{1}$ & $300^{1}$ & 59.4 & $152.7 \pm 138.6$ & 1.0 & 112.5 & 400.0 & 700.0 & $48(7.5)$ \\
\hline Potassium [mg/d] & \multicolumn{2}{|c|}{2000} & 5.0 & $147.3 \pm 140.4$ & 1.4 & 126.5 & 420.8 & 500.0 & $2(3.8)$ \\
\hline Iron $[\mathrm{mg} / \mathrm{d}]$ & 10.0 & $15.0^{2}$ & 17.1 & $4.2 \pm 4.2$ & 0.0 & 3.5 & 14.0 & 21.0 & $13(7.1)$ \\
\hline Iodine $[\mu \mathrm{g} / \mathrm{d}]$ & $200^{3}$ & $180^{3}$ & 18.4 & $64.5 \pm 43.9$ & 0.8 & 75.0 & 150.0 & 200.0 & $15(7.6)$ \\
\hline Zinc [mg/d] & 10.0 & 7.0 & 33.6 & $4.1 \pm 4.2$ & 0.4 & 2.5 & 12.5 & 30.0 & $19(5.3)$ \\
\hline Selenium $[\mu \mathrm{g} / \mathrm{d}]$ & \multicolumn{2}{|c|}{$30-70$} & 23.0 & $27.9 \pm 28.7$ & 0.3 & 25.0 & 80.0 & 200.0 & $13(5.3)$ \\
\hline Copper [mg/d] & \multicolumn{2}{|c|}{$1.0-1.5$} & 17.1 & $0.6 \pm 0.5$ & 0.0 & 0.4 & 1.4 & 2.4 & $24(13.1)$ \\
\hline Chromium [ $\mu \mathrm{g} / \mathrm{d}]$ & \multicolumn{2}{|c|}{$30-100$} & 15.0 & $25.1 \pm 23.5$ & 0.7 & 20.0 & 60.0 & 200.0 & $14(8.7)$ \\
\hline Molybdenum $[\mu \mathrm{g} / \mathrm{d}]$ & \multicolumn{2}{|c|}{$50-100$} & 14.4 & $27.0 \pm 19.6$ & 0.6 & 25.0 & 63.8 & 80.0 & $7(4.5)$ \\
\hline Manganese [mg/d] & \multicolumn{2}{|c|}{$2.0-5.0$} & 15.0 & $1.3 \pm 1.3$ & 0.0 & 1.0 & 4.0 & 5.1 & $23(14.4)$ \\
\hline
\end{tabular}

${ }^{1} 15$ - 19 years: $400 \mathrm{mg} / \mathrm{d}(\mathrm{m}) 350 \mathrm{mg} / \mathrm{d}(\mathrm{w}) ; 19$ - 25 years: $400 \mathrm{mg} / \mathrm{d}(\mathrm{m}) 310 \mathrm{mg} / \mathrm{d}(\mathrm{w}) ; 25$-> 65 years: $350 \mathrm{mg} / \mathrm{d}(\mathrm{m}) 300 \mathrm{mg} / \mathrm{d}(\mathrm{w}) ;{ }^{2} 15$ - 51 years: $15 \mathrm{mg} / \mathrm{d}$; 51 -> 65 years: $10 \mathrm{mg} / \mathrm{d} ;{ }^{3} 15$ - 51 years: $200 \mu \mathrm{g} / \mathrm{d}$; 51 -> 65 years: $180 \mu \mathrm{g} / \mathrm{d}$; * Percentage of those supplement users taking the specific mineral.

men and women. Table 2 presents the mean, median and maximum, as well as the $5^{\text {th }}$ and $95^{\text {th }}$ percentile, of mineral intake among all supplement users. In the case of the most commonly consumed minerals, the median intake was between $17 \%$ of the specific reference value for calcium and $36 \%$ for magnesium and zinc. The median iron intake in women was about $40 \%$ of the reference value of $15 \mathrm{mg} / \mathrm{d}$. Supplemental mineral intake above the $95^{\text {th }}$ percentile was sometimes higher than the specific reference value. This was the case for magnesium $(7.5 \%$ of those supplement users taking the specific mineral), zinc (5.3\%), selenium (5.3\%), copper (13.1\%), chromium (8.7\%), molybdenum (4.5\%), and manganese (14.4\%). The primary reason for supplement purchase was the desire for preservation of health and general well-being (65.8\% - 78.8\%). Other motivations were compensation for an unbalanced diet (40.1\%), medical recommendations (33.6\%) or existing diseases (37.9\%); data not shown.

Questions about frequency, duration and seasonal taking habits of the products showed that $61.3 \%$ of the products mentioned were used daily and $71.3 \%$ throughout the year. Periodic taking habits (only in summer or winter or special occasions) were only seen for $1.3 \%-9.4 \%$ of the products.

\subsection{Exceeding the UL with Supplemental Mineral Intake}

Few subjects surpassed the UL of magnesium and zinc through supplemental intake only. One male supplement user exceeded the UL of zinc with $30 \mathrm{mg} / \mathrm{d}$. This was due to the intake of a total of four products containing zinc, of which two were dietary foods for special medical purposes. The UL set for supplemental magnesium (250 $\mathrm{mg} / \mathrm{d})$ was exceeded by $22.3 \%$ ( $\mathrm{n}=62 \mathrm{men} ; \mathrm{n}=81$ women) of those supplement users taking magnesium $(\mathrm{n}=$ 274 men; $n=366$ women). In $68 \%$ of cases, the UL of magnesium was exceeded by the intake of a single preparation. The mean magnesium intake in this subgroup of supplement users exceeding the UL of magnesium was $368.0 \pm 75.8 \mathrm{mg} / \mathrm{d}$ compared to $90.2 \pm 75.9 \mathrm{mg} / \mathrm{d}$ for the subgroup with intake below the UL $(\mathrm{P}<0.001)$. Overall, subjects exceeding the UL were significantly older than those whose intake was below the UL (58.2 \pm 14.3 vs. $53.0 \pm 14.9$ years, $\mathrm{P}<0.001$ ). Additionally, the men in this group were significantly older than the women (61.8 \pm 11.9 vs. $55.5 \pm 15.4$ years, $\mathrm{P}<0.05)$. There was a weak but significant correlation between the exceeding of the UL and age $(r=0.142, \mathrm{P}<0.001)$. The percentage of subjects taking several products was greater in 
subjects exceeding the UL than those below $(\mathrm{P}<0.001)$. The average number of products recorded in this group was $2.3 \pm 1.6$ products compared to $1.5 \pm 0.9$ products from subjects below the UL. On average, those subjects were regular (76.0\% daily, $94.8 \%$ throughout the year) and long-term ( $72.8 \%$ for less than five years) users.

\subsection{Addition of Supplemental Mineral Intake to Foods}

Table 3 presents the mineral intake from supplements only, food only, and from food and supplements for the male and female supplement users. The UL set for magnesium was already exceeded from supplemental intake alone at the $95^{\text {th }}$ percentile in men and women $(400 \mathrm{mg} / \mathrm{d})$. In the middle-high intake group, the UL was only

Table 3. Mineral intake from food supplements and food.

\begin{tabular}{|c|c|c|c|c|c|c|c|c|}
\hline & \multirow[t]{2}{*}{ UL } & \multicolumn{2}{|c|}{ Intake from supplements } & \multicolumn{2}{|c|}{ Intake from food ${ }^{1}$} & \multicolumn{3}{|c|}{ Intake from food + supplements } \\
\hline & & $50^{\text {th }}$ & $95^{\text {th }}$ & $50^{\text {th }}$ & $95^{\text {th }}$ & $50^{\text {th }}+50^{\text {th }}$ & $50^{\text {th }}+95^{\text {th }}$ & $95^{\text {th }}+95^{\text {th }}$ \\
\hline \multicolumn{9}{|l|}{ Men $(n=437)$} \\
\hline Calcium [mg/d] & $2500^{2}$ & 199 & 800 & 1052 & 2061 & 1251 & 1852 & 2861 \\
\hline Phosphorus [mg/d] & $4000^{3}$ & 124 & 133 & - & - & - & - & - \\
\hline Magnesium [mg/d] & $250^{2,4}$ & 123 & 400 & 432 & 714 & 555 & 832 & 1114 \\
\hline Potassium [mg/d] & - & 75.9 & - & 3612 & 6145 & 3688 & - & - \\
\hline Iron [mg/d] & $45^{3}$ & 2.5 & 14.0 & 14.4 & 24.7 & 16.9 & 28.4 & 38.7 \\
\hline Iodine $[\mu \mathrm{g} / \mathrm{d}]$ & $600^{5}$ & 75.0 & 146 & $233^{5}$ & $412^{5}$ & 308 & 379 & 558 \\
\hline Zinc [mg/d] & $25^{2}$ & 2.5 & 15.0 & 11.6 & 20.2 & 14.1 & 26.6 & 35.2 \\
\hline Selenium $[\mu \mathrm{g} / \mathrm{d}]$ & $300^{2}$ & 25.0 & 76.0 & - & - & - & - & - \\
\hline Copper [mg/d] & $5^{2}$ & 0.5 & 1.6 & - & - & - & - & - \\
\hline Chromium [ $\mu \mathrm{g} / \mathrm{d}]$ & - & 20.0 & 60.0 & - & - & - & - & - \\
\hline Molybdenum [ $\mu \mathrm{g} / \mathrm{d}]$ & $600^{2}$ & 25.0 & 53.8 & - & - & - & - & - \\
\hline Manganese [mg/d] & $11^{3}$ & 1.0 & 4.0 & - & - & - & - & - \\
\hline \multicolumn{9}{|l|}{ Women $(n=633)$} \\
\hline Calcium [mg/d] & $2500^{2}$ & 162 & 873 & 964 & 1734 & 1126 & 1837 & 2607 \\
\hline Phosphorus [mg/d] & $4000^{3}$ & 97.7 & 133 & - & - & - & - & - \\
\hline Magnesium [mg/d] & $250^{2,4}$ & 110 & 400 & 361 & 572 & 471 & 761 & 972 \\
\hline Potassium [mg/d] & - & 150 & 474 & 3140 & 5054 & 3290 & 3614 & 5528 \\
\hline Iron [mg/d] & $45^{3}$ & 3.5 & 14.0 & 11.8 & 19.3 & 15.3 & 25.8 & 33.3 \\
\hline Iodine $[\mu \mathrm{g} / \mathrm{d}]$ & $600^{5}$ & 71.9 & 150 & $185^{5}$ & $310^{5}$ & 257 & 335 & 460 \\
\hline Zinc [mg/d] & $25^{2}$ & 2.5 & 10.0 & 9.1 & 15.1 & 11.6 & 19.1 & 25.1 \\
\hline 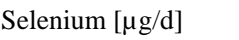 & $300^{2}$ & 25.0 & 83.6 & - & - & - & - & - \\
\hline Copper [mg/d] & $5^{2}$ & 0.3 & 1.4 & - & - & - & - & - \\
\hline Chromium [ $\mu \mathrm{g} / \mathrm{d}]$ & - & 20.0 & 60.0 & - & - & - & - & - \\
\hline Molybdenum [ $\mu \mathrm{g} / \mathrm{d}]$ & $600^{2}$ & 25.0 & 75.0 & - & - & - & - & - \\
\hline Manganese [mg/d] & $11^{3}$ & 1.0 & 4.0 & - & - & - & - & - \\
\hline
\end{tabular}

${ }^{1}$ Data from the German National Nutrition Survey II [9]; ${ }^{2}$ EFSA, SCF tolerable upper intake levels for vitamins and minerals [16] [22]; ${ }^{3}$ Food and Nutrition Board, Institute of Medicine [20] [21]; ${ }^{4}$ Intakes from supplements only; ${ }^{5}$ Including salt fortification in the diet; Values of mineral intake exceeding the UL are in bold. 
reached for zinc in men $(26.6 \mathrm{mg} / \mathrm{d})$, and in the high intake group, the UL was exceeded for calcium $(2861 \mathrm{mg} / \mathrm{d}$ men; $2607 \mathrm{mg} / \mathrm{d}$ women) and zinc (35.2 mg/d men; $25.1 \mathrm{mg} / \mathrm{d}$ women). A closer inspection of the subjects who exceeded the $95^{\text {th }}$ percentile of calcium $(n=23)$, magnesium $(n=48)$ and zinc $(n=34)$ intake (Table 4$)$ displays

Table 4. Characteristics of supplement users above the $95^{\text {th }}$ percentile of calcium, magnesium and zinc intake.

\begin{tabular}{|c|c|c|c|}
\hline Calcium & & & \\
\hline \multirow[t]{2}{*}{$\geq 95^{\text {th }}$ percentile of calcium intake } & $\mathrm{m}$ & $\geq 800 \mathrm{mg}$ & $\mathrm{n}=11$ \\
\hline & $\mathrm{w}$ & $\geq 873 \mathrm{mg}$ & $\mathrm{n}=12$ \\
\hline \multirow[t]{2}{*}{ Mean calcium intake [mg/d] } & $\mathrm{m}$ & $866.5 \pm 86.3$ & \\
\hline & $\mathrm{w}$ & $1037.6 \pm 116.4$ & $\mathrm{P}=0.001^{1}$ \\
\hline \multirow[t]{2}{*}{ Mean number of products [n] } & $\mathrm{m}$ & $3.6 \pm 3.0$ & \\
\hline & $\mathrm{w}$ & $2.2 \pm 1.2$ & \\
\hline \multicolumn{4}{|l|}{ Products were taken } \\
\hline Daily & & $77.7 \%$ & \\
\hline Throughout the year & & $84.3 \%$ & \\
\hline$<5$ years & & $54.4 \%$ & \\
\hline$<1$ year & & $34.9 \%$ & \\
\hline \multicolumn{4}{|l|}{ Magnesium } \\
\hline \multirow[t]{2}{*}{$\geq 95^{\text {th }}$ percentile of magnesium intake } & $\mathrm{m}$ & $\geq 400 \mathrm{mg}$ & $\mathrm{n}=24$ \\
\hline & $\mathrm{w}$ & $\geq 400 \mathrm{mg}$ & $\mathrm{n}=24$ \\
\hline \multirow[t]{2}{*}{ Mean magnesium intake [mg/d] } & $\mathrm{m}$ & $441.0 \pm 65.4$ & \\
\hline & $\mathrm{w}$ & $446.7 \pm 76.6$ & $\mathrm{P}=0.991^{1}$ \\
\hline \multirow[t]{2}{*}{ Mean number of products [n] } & $\mathrm{m}$ & $2.5 \pm 1.9$ & \\
\hline & $\mathrm{w}$ & $2.2 \pm 0.9$ & \\
\hline \multicolumn{4}{|l|}{ Products were taken } \\
\hline Daily & & $81.2 \%$ & \\
\hline Throughout the year & & $94.6 \%$ & \\
\hline$<5$ years & & $67.1 \%$ & \\
\hline$<1$ year & & $37.2 \%$ & \\
\hline \multicolumn{4}{|l|}{ Zinc } \\
\hline \multirow[t]{2}{*}{$\geq 95^{\text {th }}$ percentile of zinc intake } & $\mathrm{m}$ & $\geq 15.0 \mathrm{mg}$ & $\mathrm{n}=9$ \\
\hline & $\mathrm{w}$ & $\geq 10.0 \mathrm{mg}$ & $\mathrm{n}=25$ \\
\hline \multirow[t]{2}{*}{ Mean zinc intake [mg/d] } & $\mathrm{m}$ & $18.0 \pm 5.0$ & \\
\hline & $\mathrm{w}$ & $12.2 \pm 3.3$ & $\mathrm{P}<0.001^{1}$ \\
\hline \multirow[t]{2}{*}{ Mean number of products [n] } & $\mathrm{m}$ & $3.3 \pm 1.8$ & \\
\hline & $\mathrm{w}$ & $2.4 \pm 1.8$ & \\
\hline \multicolumn{4}{|l|}{ Products were taken } \\
\hline Daily & & $71.5 \%$ & \\
\hline Throughout the year & & $74.0 \%$ & \\
\hline$<5$ years & & $67.5 \%$ & \\
\hline$<1$ year & & $39.2 \%$ & \\
\hline
\end{tabular}

${ }^{1}$ Mann-Whitney U test. 
that the preparations were mostly taken daily, over the entire year and for less than five years. The average number of products in this subgroup was $2.9 \pm 2.3$ for calcium, $2.4 \pm 1.5$ for magnesium and $2.7 \pm 1.8$ for zinc. Women had significantly higher mean calcium intakes whereas men had significantly higher mean zinc intakes. In eight cases, supplemental calcium intakes above the $95^{\text {th }}$ percentile resulted from the use of two products with calcium (1× specific calcium preparation, 1× multi-compounds preparation). The other 15 subjects only used one calcium preparation containing a dose between 800 and $1000 \mathrm{mg}$. Accordingly, the zinc intake above the $95^{\text {th }}$ percentile derived from the use of two products containing zinc $(n=12)$, three products containing zinc $(n=$ 2) or one preparation with 10 - $15 \mathrm{mg}$ zinc each $(\mathrm{n}=20)$.

\section{Discussion}

The objectives of the present study were to evaluate the mean mineral intake of supplement users and whether there are possible risks involved. Therefore, the prevalence of subjects which exceeded the specific UL of minerals by supplement intake alone and by addition of the intake from diet and supplements was assessed. Detailed and actual compositional information of the products mentioned individually were used for the calculation of the specific mineral amounts.

In agreement with previous studies in Germany [1] [24]-[26], more women (59.2\%) used supplements than men (40.8\%). Moreover, an increasing use of supplements was observed with increasing age. Here, the proportion of men and women over the age of 50 years was $70.7 \%$ and $54.3 \%$, respectively. Unlike most comparable surveys, however, the percentage of men was higher in the age groups $51-64$ and $\geq 65$ years. Studies from Denmark [4], England [3], Canada [27], and Germany [1] [8] identified women in the age group of 50 - 75 years as the most common supplement users.

Multiple use of food supplements due to the intake of several products at the same time are discussed as a potential risk of excessive nutrient intake. Data of multiple uses were acquired in this survey. Approximately 69\% of the subjects consumed only one supplement. This proportion is slightly higher compared to other studies [28] [29]: the prevalence of supplement users taking only one preparation was 57.5\% [28] and 54.8\% [29]. It was found for several products that men used them statistically significantly more often than women. This is in contrast to previous surveys, in which elderly women were more likely to use multiple supplements [28]-[31]. One reason for this discrepancy could be the inclusion of drugs containing calcium and vitamin $\mathrm{D}$, which are more often consumed by women due to osteoporosis prophylaxis, in former studies [2] [8] [29]. Overall, multiple use played a minor role when considering the totality of subjects. However, taking into account the most frequent minerals recorded (magnesium, calcium, selenium, and zinc) and those subgroups in which the UL was reached, respectively exceeded in a few cases for magnesium, calcium and zinc, an increase of multiple use was observed. In this context, elderly subjects using several supplements are possibly a population at high risk for exceeding ULs. Furthermore, from the fact that, overall, most supplements were consumed daily (61.3\%), throughout the year (71.3\%) and for at least one year (56.1\%), consistently high levels of mineral intake from supplements are to be considered for specific subgroups.

The intake of vitamins and minerals from food supplements can be used to improve nutritional status in case of insufficient intake by diet. In this survey, the median mineral intake from supplements ranged from 6.4\% (e.g. potassium) to $83.3 \%$ (e.g. selenium) of the respective national reference values. The mean mineral intake was not statistically different between men and women. Moreover, it is notable that the mean selenium intake from food supplements $(27.9 \pm 28.7 \mu \mathrm{g} / \mathrm{d})$ is quite close to the lowest national reference value $(30-70 \mu \mathrm{g} / \mathrm{d})$. However, these recommendations are estimates by definition. Furthermore, it must be noted that current nutritional data were not available for selenium intake in the German population. Thus, an accurate interpretation is not possible.

Additionally, the $95^{\text {th }}$ percentile of iron intake from food was proportionately high in men (24.7 mg/d). Thus, the total intake of iron in the high intake group $(38.7 \mathrm{mg} / \mathrm{d})$ consequently results in a high level as well, but still did not exceed the UL of $45 \mathrm{mg} / \mathrm{d}$ from the FNB/IOM.

The median food intake did not change substantially by the addition of the median supplemental intake. The consumption of food supplements even in the middle-high and high intake ("worst case scenario") groups did not result in excessive intakes, except for calcium $(n=23)$ and zinc $(n=34)$. This is of importance, as an excessive dose of calcium may cause adverse effects, such as kidney stones, hypercalcaemia and interactions between dietary minerals [16]. Side-effects in humans from excessive zinc intake are divided into acute and chronic effects. Acute toxicity is uncommon and primarily related to gastrointestinal symptoms, whereas chronic toxicity 
is associated with impaired immune function, and altered lipoprotein and copper metabolism [16] [32]. It was not unexpected to observe excessive intakes of calcium and zinc, since the ULs are quite low and close to the respective national reference values. Additionally, it must be noted that higher calcium and zinc intake levels partially resulted from the use of single mono-preparations. This is of relevance for the discussion of maximum nutrient levels in food supplements. Maximum levels would help to further minimise the risk of exceeding the UL. However, the "worst case scenario" of high mineral intake from food sources and food supplements is of practical relevance as food supplements are normally used by health conscious individuals with a higher educational level and with an already high nutrient intake by diet [8] [17] [33] [34]. Otherwise, people with the lowest dietary intake and with the greatest need would benefit most. When adding up the intakes from food supplements and food, it should be emphasized as a weakness that there is only a reference to the secondary data of the National Nutrition Survey II [9], and we did not use person-related data about the individual nutrient intake from food. This can therefore be regarded as an estimate only. Indeed, nearly identical results have been reached, when the high intake levels were calculated with the primary data of the food and supplemental intakes both from the National Nutrition Survey II. In the case of calcium, iron, iodine, and zinc even higher intake values have been achieved.

The sole use of food supplements did not generally increase the mineral intake above the UL, except for magnesium (>250 mg/d). Single doses of magnesium (>250 mg/d), induced by easily dissociable magnesiumsalts, can cause osmotic diarrhoea, which are reversible. Toxic hypermagnesaemia can only be seen with single oral doses $>2500 \mathrm{mg}$ [16]. A percentage of 13.4 of the supplement users were observed to exceed the UL. These results are consistent with findings of other investigators. Food supplement use of magnesium, calcium and zinc increased the likelihood of total intakes above the UL [17] [31] [35]. Overall, food supplement use increases with age and the multiple use of supplements even more. Here again, older adults may be more likely to have excessive intake of some minerals.

The majority of study results relating to nutrient intake only include the intake of nutrients from diet and/or supplements. There is very little information available about the consumption of fortified foods in combination with dietary intake and food supplement use [7] [9] [36] [37]. This should be taken into account in further studies. Enriched foods bear a substantial share of the supply of some nutrients [9] [37]. Therefore, nutrient intake from food is likely to be underestimated. In this survey, fortified foods were partially considered, as the National Nutrition Survey II [9] included fortified foods, such as enriched juices or cereals, in their calculations.

As already mentioned, a limitation of this study is the use of data from different sources. In this case, the data were used to perform a theoretical risk calculation model (addition of percentiles). For Germany there are no other food intake data than the NVS II data available. Moreover, this national nutrition survey had a sufficiently large sample required to represent the nutrition situation in Germany. However, the calculation model has weaknesses due to the use of secondary data.

Additionally, it is critical to compare a mineral intake from a mixed diet across the day with a daily single-dose from food supplements, as has been done in the "worst case scenario". The individual bioavailability of several minerals, dependent on their chemical form, plays an important role but has not been considered here.

\section{Conclusion}

According to the data collected, food supplements and related product groups are particularly consumed to maintain or improve health. In this survey, the mineral intake from food supplements additional to the intake from the diet bears no overall risk of overdose. The data show that multi-exposure is not a widespread issue. The estimated intake of high doses was observed only in individual cases for magnesium, calcium and zinc. However, in the case of magnesium, the recommended maximum amount for food supplements was more frequently exceeded. Even if only few cases were dangerously affected, there was a need for professional advice regarding a rational choice of food supplements and for setting EU-wide maximum levels.

\section{Competing Interests}

The authors declare that they have no competing interests.

\section{Acknowledgements}

The project was partially funded by the German Federation of Food Law and Food Science (Bund für Le- 
bensmittelrecht und Lebensmittelkundee. V., BLL). We thank the Association for Consumer, Marketing and Sales Research (GfK) for the organization and execution of the nationwide survey.

\section{References}

[1] Schwab, S., Heier, M., Schneider, A., Fischer, B., Huth, C., Peters, A. and Thorand, B. (2014) The Use of Dietary Supplements among Older Persons in Southern Germany-Results from the KORA-Age Study. The Journal of Nutrition Health and Aging, 18, 510-519. http://dx.doi.org/10.1007/s12603-013-0418-8

[2] Giammarioli, S., Boniglia, C., Carratù, B., Ciarrocchi, M., Chiarotti, F., Mosca, M. and Sanzini, E. (2013) Use of Food Supplements and Determinants of Usage in a Sample Italian Adult Population. Public Health Nutrition, 16, 1768-1781. http://dx.doi.org/10.1017/S1368980012004314

[3] Denison, H.J., Jameson, K.A., Syddall, H.E., Dennison, E.M., Cooper, C., Sayer, A.A. and Robinson, S.M. (2012) Patterns of Dietary Supplement Use among Older Men and Women in the UK: Findings from the Hertfordshire Cohort Study. The Journal of Nutrition Health and Aging, 16, 307-311. http://dx.doi.org/10.1007/s12603-012-0016-1

[4] Tetens, I., Biltoft-Jensen, A., Spagner, C., Christensen, T., Gille, M., Bügel, S. and Banke, R.L. (2011) Intake of Micronutrients among Danish Adult Users and Non-Users of Dietary Supplements. Food Nutrition Research, 55, 1. http://dx.doi.org/10.3402/fnr.v55i0.7153

[5] Marques-Vidal, P., Pécoud, A., Hayoz, D., Paccaud, F., Mooser, V., Waeber, G. and Vollenweider, P. (2009) Prevalence and Characteristics of Vitamin or Dietary Supplement Users in Lausanne, Switzerland: The CoLaus Study. European Journal of Clinical Nutrition, 63, 273-281. http://dx.doi.org/10.1038/sj.ejcn.1602932

[6] Messerer, M., Johansson, S.E. and Wolk, A. (2001) Sociodemographic and Health Behaviour Factors among Dietary Supplement and Natural Remedy Users. European Journal of Clinical Nutrition, 55, 1104-1110. http://dx.doi.org/10.1038/sj.ejcn.1601272

[7] Flynn, A., Hirvonen, T., Mensink, G.B.M., Ocké, M.C., Serra-Majem, L., Stos, K., Szponar, L., Tetens, I., Turrini, A., Fletcher, R. and Wildemann, T. (2009) Intake of Selected Nutrients from Foods, from Fortification and from Supplements in Various European Countries. Food Nutrition Research, 53, 1-51.

http://dx.doi.org/10.3402/fnr.v53i0.2038

[8] Reinert, A., Rohrmann, S., Becker, N. and Linseisen, J. (2007) Lifestyle and Diet in People Using Dietary Supplements: A German Cohort Study. European Journal of Nutrition, 46, 165-173. http://dx.doi.org/10.1007/s00394-007-0650-2

[9] Max Rubner Institute (2008) National Nutrition Survey II. Final Report Part 2. Nationale Verzehrsstudie II. Ergebnisbericht Teil 2. (In German) http://www.was-esse-ich.de/uploads/media/NVSII_Abschlussbericht_Teil_2.pdf

[10] Ströhle, A. and Hahn, A. (2013) Nutrient Supplements-Possibilities and Limitations. Part 1: From the Regulatory Framework to Supplementary Function. Nährstoffsupplemente-Möglichkeiten und Grenzen. Teil 1: Von den rechtlichen Rahmenbedingungen zur Ergänzungsfunktion. Medizinische Monatsschrift für Pharmazeuten, 36, 179-190. (In German)

[11] Kelly, J.P., Kaufman, D.W., Kelley, K., Rosenberg, L., Anderson, T.E. and Mitchell, A.A. (2005) Recent Trends in Use of Herbal and Other Natural Products. Archives of Internal Medicine, 165, 281-286. http://dx.doi.org/10.1001/archinte.165.3.281

[12] Shakur, Y.A., Tarasuk, V., Corey, P. and O’Connor, D.L. (2012) A Comparison of Micronutrient Inadequacy and Risk of High Micronutrient Intakes among Vitamin and Mineral Supplement Users and Nonusers in Canada. Journal of Nutrition, 142, 534-540. http://dx.doi.org/10.3945/jn.111.149450

[13] Touvier, M., Boutron-Ruault, M.C., Volatier, J.L. and Martin, A. (2005) Efficacy and Safety of Regular Vitamin and Mineral Supplement Use in France: Results from the ECCA Study. International Journal for Vitamin and Nutrition Research, 75, 201-209. http://dx.doi.org/10.1024/0300-9831.75.3.201

[14] Kiely, M., Flynn, A., Harrington, K.E., Robson, P.J., O’Connor, N., Hannon, E.M., O’Brien, M.M., Bell, S. and Strain, J.J. (2001) The Efficacy and Safety of Nutritional Supplement Use in a Representative Sample of Adults in the North/ South Ireland Food Consumption Survey. Public Health Nutrition, 4, 1089-1097.

[15] Renwick, A.G. (2006) Toxicology of Micronutrients: Adverse Effects and Uncertainty. Journal of Nutrition, 136, S493-S501.

[16] EFSA Scientific Committee on Food (2006) Tolerable Upper Intake Levels for Vitamins and Minerals. http://www.efsa.europa.eu/de/ndatopics/docs/ndatolerableuil.pdf

[17] Bailey, R.L., Gahche, J.J., Lentino, C.V., Dwyer, J.T., Engel, J.S., Thomas, P.R., Beth, J.M., Sempos, C.T. and Picciano, M.F. (2011) Dietary Supplement Use in the United States, 2003-2006. Journal of Nutrition, 141, 261-266. http://dx.doi.org/10.3945/jn.110.133025

[18] Wallace, T.C., McBurney, M. and Fulgoni 3rd, V.L. (2014) Multivitamin/Mineral Supplement Contribution to Micro- 
nutrient Intakes in the United States, 2007-2010. Journal of the American College of Nutrition, 33, 94-102. http://dx.doi.org/10.1080/07315724.2013.846806

[19] German Nutrition Society, Austrian Nutrition Society, Swiss Society for Nutrition Research, Swiss Nutrition Association-DACH (2013) Reference Values for Nutrient Intake. DACH Referenzwerte für die Nährstoffzufuhr. Neustadt an der Weinstraße: Neuer Umschau Buchverlag. (In German)

[20] Food and Nutrition Board/Institute of Medicine (2001) Dietary Reference Intakes for Vitamin A, Vitamin K, Arsenic, Boron, Chromium, Copper, Iodine, Iron, Manganese, Molybdenum, Nickel, Silicon, Vanadium, and Zinc. National Academy Press, Washington DC.

[21] Food and Nutrition Board/Institute of Medicine (1997) Dietary Reference Intakes for Calcium, Phosphorus, Magnesium, Vitamin D, and Fluoride. National Academy Press, Washington DC.

[22] Scientific Committee on Food (2001) Opinion on the Tolerable Upper Intake Level of Magnesium. http://ec.europa.eu/food/fs/sc/scf/out105_en.pdf

[23] Heinemann, M., Willers, J., Bitterlich, N. and Hahn, A. (2014) Use of Food Supplements with Vitamins and Minerals - Results of a Nationwide Consumer Survey. Verwendung von Nahrungsergänzungsmitteln mit Vitaminen und Mineralstoffen-Ergebnisse einer deutschlandweiten Verbraucherbefragung. Journal für Verbraucherschutz und Lebensmittelsicherheit. (In German)

[24] Beitz, R., Mensink, G.B.M., Hintzpeter, B., Fischer, B. and Erbersdobler, H.F. (2004) Do Users of Dietary Supplements Differ from Nonusers in Their Food Consumption? European Journal of Epidemiology, 19, 335-341. http://dx.doi.org/10.1023/B:EJEP.0000024698.76843.3b

[25] Beitz, R., Mensink, G.B.M., Fischer, B. and Thamm, M. (2002) Vitamins-Dietary Intake and Intake from Dietary Supplements in Germany. European Journal of Clinical Nutrition, 56, 539-545. http://dx.doi.org/10.1038/sj.ejcn.1601346

[26] Mensink, G.B.M. and Ströbel, A. (1999) Intake of Dietary Supplements and Nutritional Behaviour. Einnahme von Nahrungsergänzungspräparaten und Ernährungsverhalten. Gesundheitswesen, 61, S132-S137. (In German)

[27] Guo, X., Willows, N., Kuhle, S., Jhangri, G. and Veugelers, P.J. (2009) Use of Vitamin and Mineral Supplements among Canadian Adults. Canadian Journal of Public Health, 100, 357-360.

[28] Schwarzpaul, S., Strassburg, A., Lührmann, P.M. and Neuhäuser-Berthold, M. (2006) Intake of Vitamin and Mineral Supplements in an Elderly German Population. Annals of Nutrition and Metabolism, 50, 155-162. http://dx.doi.org/10.1159/000090728

[29] Knudsen, V.K., Rasmussen, L.B., Haraldsdóttir, J., Ovesen, L., Bülow, I., Knudsen, N., Jørgensen, T., Laurberg, P. and Perrild, H. (2002) Use of Dietary Supplements in Denmark Is Associated with Health and Former Smoking. Public Health Nutrition, 5, 463-468. http://dx.doi.org/10.1079/PHN2001276

[30] Timbo, B.B., Ross, M.P., McCarthy, P.V. and Lin, C.T. (2006) Dietary Supplements in a National Survey: Prevalence of Use and Reports of Adverse Events. Journal of the Academy of Nutrition and Dietetics, 106, 1966-1974. http://dx.doi.org/10.1016/j.jada.2006.09.002

[31] Burnett-Hartman, A.N., Fitzpatrick, A.L., Gao, K., Jackson, S.A. and Schreiner, P.J. (2009) Supplement Use Contributes to Meeting Recommended Dietary Intakes for Calcium, Magnesium, and Vitamin C in Four Ethnicities of Middle-Aged and Older Americans: The Multi-Ethnic Study of Atherosclerosis. Journal of the Academy of Nutrition and Dietetics, 109, 422-429. http://dx.doi.org/10.1016/j.jada.2008.11.023

[32] Plum, L.M., Rink, L. and Haase, H. (2010) The Essential Toxin: Impact of Zinc on Human Health. International Journal of Environmental Research and Public Health, 7, 1342-1365. http://dx.doi.org/10.3390/ijerph7041342

[33] Bailey, R.L., Gahche, J.J., Miller, P.E., Thomas, P.R. and Dwyer, J.T. (2013) Why US Adults Use Dietary Supplements. JAMA Internal Medicine, 173, 355-361. http://dx.doi.org/10.1001/jamainternmed.2013.2299

[34] Rock, C.L. (2007) Multivitamin-Multimineral Supplements: Who Uses Them? American Journal of Clinical Nutrition, 85, S277-S279.

[35] Sebastian, R.S., Cleveland, L.E., Goldman, J.D. and Moshfegh, A.J. (2007) Older Adults Who Use Vitamin/Mineral Supplements Differ from Nonusers in Nutrient Intake Adequacy and Dietary Attitudes. Journal of the Academy of Nutrition and Dietetics, 107, 1322-1332. http://dx.doi.org/10.1016/j.jada.2007.05.010

[36] Berner, L.A., Keast, D.R., Bailey, R.L. and Dwyer, J.T. (2014) Fortified Foods Are Major Contributors to Nutrient Intakes in Diets of US Children and Adolescents. Journal of the Academy of Nutrition and Dietetics, 114, 1009-1022. http://dx.doi.org/10.1016/j.jand.2013.10.012

[37] Freisling, H., Elmadfa, I. and Schmid, I.T. (2008) A High Proportion of Nutrient-Enriched Food in the Vitamin Supply of Austrian Adults. Nährstoffangereicherte Lebensmittel haben einen hohen Anteil an der Vitaminversorgung bei österreichischen Erwachsenen. Ernährungs Umschau, 55, 158-164. (In German) 
Scientific Research Publishing (SCIRP) is one of the largest Open Access journal publishers. It is currently publishing more than 200 open access, online, peer-reviewed journals covering a wide range of academic disciplines. SCIRP serves the worldwide academic communities and contributes to the progress and application of science with its publication.

Other selected journals from SCIRP are listed as below. Submit your manuscript to us via either submit@scirp.org or Online Submission Portal.
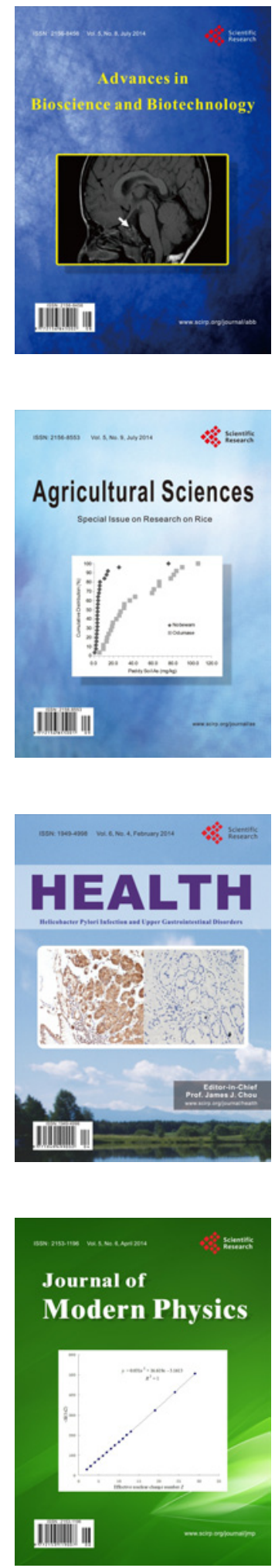
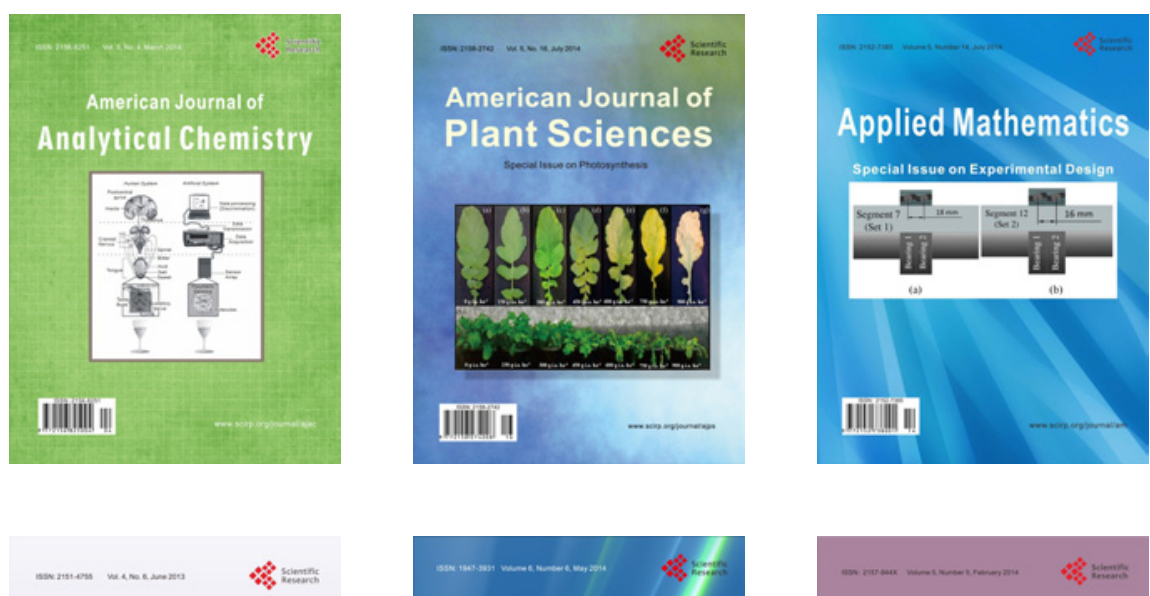

Creative Education
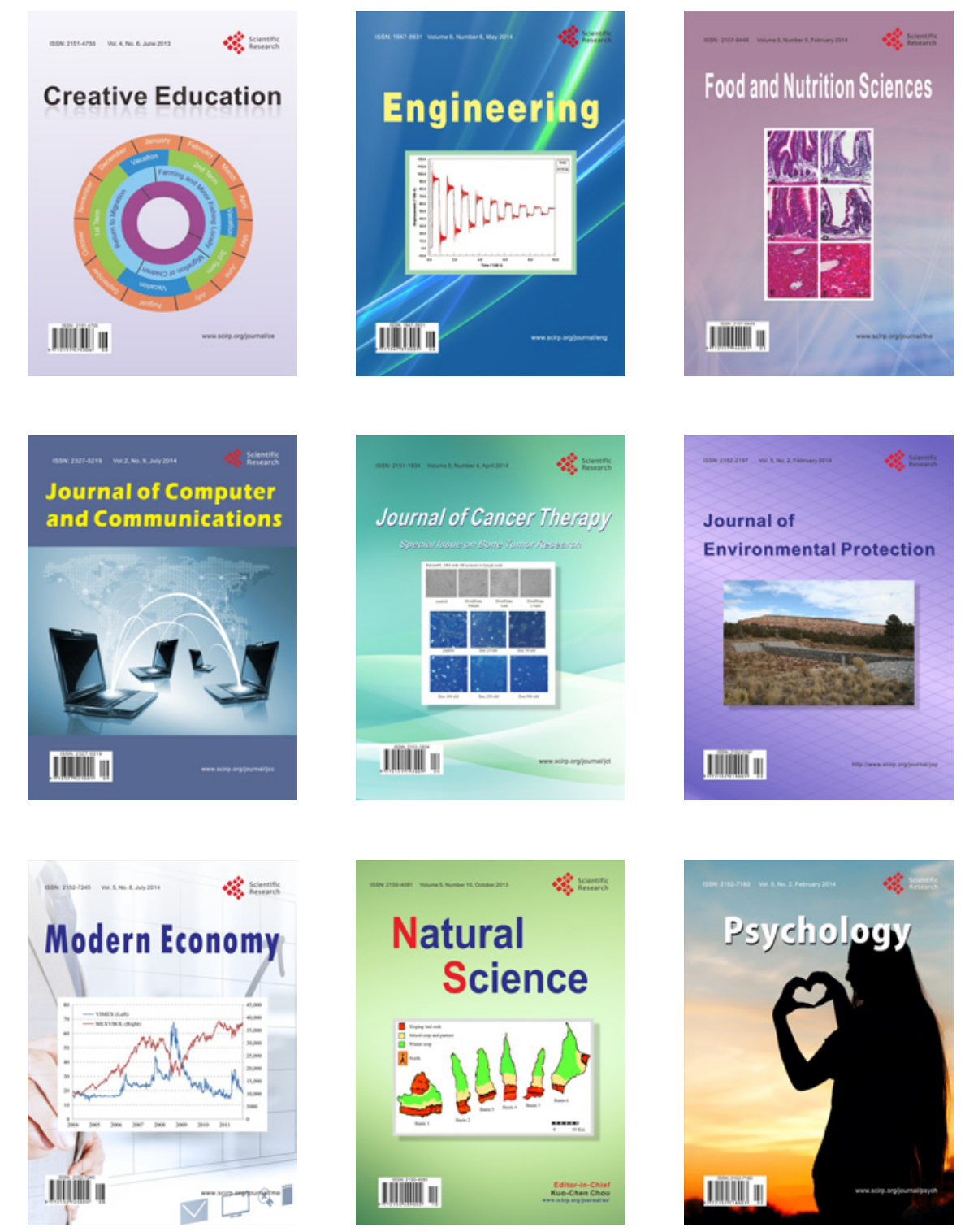